\title{
Identification of Urinary Modified \\ Nucleosides and Ribosylated Metabolites in \\ Humans Via Combined ESI-FTICR MS and \\ ESI-IT MS Analysis
}

\author{
Dino Bullinger, ${ }^{a}$ Richard Fux, ${ }^{a}$ Graeme Nicholson, ${ }^{b}$ Stefan Plontke, ${ }^{c}$ \\ Claus Belka, ${ }^{\text {d Stefan Laufer, }}{ }^{\text {e Christoph H. Gleiter, }}{ }^{\text {a }}$ and \\ Bernd Kammerer ${ }^{a}$ \\ ${ }^{a}$ Department of Clinical Pharmacology, Institute of Pharmacology and Toxicology, University Hospital \\ Tübingen, Tübingen, Germany \\ b Institute of Organic Chemistry, University of Tübingen, Tübingen, Germany \\ c Department of Otorhinolaryngology, Head and Neck Surgery, University Hospital Tübingen, Tübingen \\ Hearing Research Center (THRC), Tübingen, Germany \\ d Department of Radiation Oncology, University Hospital Tübingen, Tübingen, Germany \\ ' Institute of Pharmacy, University of Tübingen, Tübingen, Germany
}

The physiological response of the human body to several diseases can be reflected by the metabolite pattern in biological fluids. Cancer, like other diseases accompanied by metabolic disorders, causes characteristic effects on cell turnover rate, activity of modifying enzymes, and RNA/DNA modifications. This results in an altered excretion of modified nucleosides and biochemically related compounds. In the course of our metabolic profiling project, we screened 24-h urine of patients suffering from lung, rectal, or head and neck cancer for previously unknown ribosylated metabolites. Therefore, we developed a sample preparation procedure based on boronate affinity chromatography followed by additional prepurification with preparative TLC. The isolated metabolites were analyzed by ion trap mass spectrometry (IT MS) and Fourier transform ion cyclotron resonance mass spectrometry (FTICR MS). IT MS was applied for LC-auto $\mathrm{MS}^{3}$ screening runs and $\mathrm{MS}^{n(n=4-6)}$ syringe pump infusion experiments, yielding characteristic fragmentation patterns. FTICR MS measurements enabled the calculation of corresponding molecular formulae based on accurate mass determination (mass accuracy: 1-5 ppm for external and sub-ppm values for internal calibration). We were able to identify 22 metabolites deriving from cellular RNA metabolism and related metabolic pathways like histidine metabolism, purine biosynthesis, methionine/polyamine cycle, and nicotinate/nicotinamide metabolism. The compounds 1-ribosyl-3-hydroxypyridinium, 1-ribosyl-pyridinium, and 3-ribosyl-1-methyl-Lhistidinium as well as a series of ribosylated histamines, conjugated to carboxylic acids at the $\mathrm{N}^{\omega}$-position were found as novel urinary constituents. The occurrence of the modified nucleosides 2-methylthio- $N^{6}$-(cis-hydroxyisopentenyl)-adenosine, 5-methoxycarbonylmethyl-2-thiouridine, $N^{6}$-methyl- $N^{6}$-threonylcarbamoyladenosine, and 2-methylthio- $N^{6}$-threonylcarbamoyladenosine in human urine is verified for the first time. (J Am Soc Mass Spectrom 2008, 19, 1500-1513) @ 2008 American Society for Mass Spectrometry

$\mathrm{T}$ The clinical research for reliable biomarkers in early diagnosis and therapy surveillance of cancer diseases is a rapidly emerging field since many of the presently applied marker compounds show only unsatisfactory prediction values. Screening the genomic profile (genomics) $[1,2]$ and the expressed protein pattern (proteomics) $[3,4]$ for characteristic

Data of ethics proposal: request number of ethics commission: $280 / 2005 \mathrm{~V}$, date of agreement: 31.10.2005.

Address reprint requests to Dr. B. Kammerer, Department of Clinical Pharmacology, University Hospital Tübingen, Institute of Pharmacology and Toxicology, Otfried-Müller Str. 45, D-72076 Tübingen, Germany. E-mail: Bernd.Kammerer@uni-tuebingen.de alterations associated with severe pathophysiological changes are well-defined concepts in clinical cancer research. Recently, the metabolome, represented by the end products of gene-/protein expression and the biochemical phenotype of a cell or tissue, has experienced increasing interest [5-7].

The corresponding research area of metabolomics is defined as the comprehensive identification and quantification of all metabolites of a biological system [8]. Considering the wide range of chemical and physical properties of various metabolite classes, this analytical scope is still challenging. A more viable aspect of the metabolomics concept is the metabolic profiling ap- 
proach, defined as the identification and quantification of a subset of metabolites belonging to a selected metabolic pathway [8].

Possible targets for metabolic profiling related to neoplastic cancer diseases are compounds originating from cellular RNA metabolism. The resulting ribonucleoside metabolites are released post-transcriptionally due to stepwise enzymatic degradation of the polynucleotide macromolecules. Whereas the common nucleosides cytidine, uridine, adenosine, and guanosine are recycled for intracellular RNA-rebuilding, their modified counterparts are quantitatively excreted from the cell as metabolic endproducts. Altered levels of modified nucleosides in biological fluids have been demonstrated in association with various types of cancer [9-12]. This phenomenon is generally attributed to the increased RNA turnover rate and activity of modifying enzymes in tumor cells $[13,14]$. Besides the quantitative analysis of the nucleoside pattern, the search for previously unknown, cancer-specific modifications is a promising approach. Dudley et al. identified the novel nucleoside structure 5 -deoxycytidine in the urine of a patient with terminal head and neck cancer [15]. In urine of cancer patients in other stages of the disease and of healthy volunteers, this modified nucleoside was not detectable and thus might be directly related to the tumor stage and development [5'-deoxycytidine could not be detected in the analyzed urine samples of this study].

Methods like high-performance liquid chromatography (HPLC) with UV detection [16, 17] and capillary electrophoresis (CE) [18] have been applied for the analysis of ribonucleosides. Recently, the coupling of HPLC with mass spectrometric detection via electrospray ionization ion trap mass spectrometry (ESI-IT MS) $[15,19]$, ESI tandem MS [20, 21], and fast atom bombardment (FAB) $[22,23]$ has been established. Sophisticated mass spectrometric setups like ESI-oa-TOF MS [24] and MALDI-TOF MS [25] have already proven to be valuable tools for the structural elucidation of RNA metabolites. To date, about 100 modified nucleoside structures have been identified, originating from different RNA species [26].

In general, the analysis of urinary metabolite patterns has to be interpreted carefully because of various possible interferences along the excretion pathway. Biotransformation reactions in the bloodstream, liver, and kidney as well as other endogenous influences (e.g., formation of secondary metabolites from endosymbionic bacteria in humans) can affect and falsify the metabolic profile. Consequently, when selecting urinary compounds for cancer biomarker studies, both structural identification of the metabolites and knowledge of their biochemical origin are of utmost importance for the reliability of clinical prediction.

For this purpose, we developed a method for the identification of ribosylated metabolites in the 24-h urine of tumor patients suffering from lung, rectal, or head and neck cancer. Structural elucidation was achieved by combining accurate mass determination via FTICR MS and characteristic fragmentation patterns, generated by IT MS. The applied boronate affinity chromatography generally isolates a broad spectrum of cis-diol metabolites, mainly ribose conjugated. Besides several RNA metabolites, we were able to identify compounds originating from interconnected metabolic pathways [27] like the histidine metabolism, the purine biosynthesis, and the methionine/polyamine cycle as well as from the nicotinate/nicotinamide metabolism.

\section{Experimental}

\section{Urine Samples}

The 24-h urine samples were obtained from the Departments of Radiation Oncology and Otorhinolaryngology and Head and Neck Surgery at the University Hospital Tübingen.

To minimize possible endo- and exogenous perturbations on the urinary metabolite pattern, we defined precise criteria for patient recruitment. The samples from male and female patients suffering from lung $(n=$ $2, \mathrm{~T} 2, \mathrm{~T} 4)$, rectal $(n=4$, all T3), or head and neck cancer ( $n=3$, T3, 2x T4) were taken preoperatively with no neoadjuvant hormonal, irradiation, or chemotherapy applied. Patients taking immunomodulating drugs, antibiotics, mistletoe preparations, virustatics, allopurinol, and dipyridamole were not included in this study. Pregnancy, immune mediated diseases, HIV, acute and chronic hepatitis, chronic renal failure, acute infection of the urinary tract as well as the patients' participation in a clinical drug trial also resulted in the exclusion from the study. Particular nutrition aspects were not considered except for the documentation of smoking behavior.

The patients collected the urine over a period of $24 \mathrm{~h}$, using the UriSet24 (Sarstedt, Nümbrecht, Germany). The obtained samples were immediately analyzed after termination of the collection period.

\section{Chemicals}

Methanol for liquid chromatography (LiChrosolv, hypergrade), methanol for affinity chromatography (LiChroSolv, gradient grade), acetonitrile for preparative TLC (LiChrosolv, gradient grade), ammonium acetate (extra pure), and formic acid (extra pure) were purchased from Merck/VWR (Darmstadt, Germany). Ammonium formate (puriss. p.a., for mass spectrometry) was obtained from Fluka (Taufkirchen, Germany). Water was taken from an in-house double distillation system.

Commercially available standards used as reference for compound identification via retention time and/or IT $\mathrm{MS}^{n}$ fragmentation patterns were 2-hydroxypyridine, 3hydroxypyridine, 4-hydroxypyridine, $N$ - $\omega$-acetylhistamine, $N^{6}$-methyladenosine ( $\left.\mathrm{m}^{6} \mathrm{~A}\right)$, 1-ribosyl-4-carboxamido-5aminoimidazole (AICA riboside), adenylosuccinic acid (sodium salt), imidazole-4-acetic acid (sodium salt), and 
nicotinamide (all obtained from Sigma, Taufkirchen, Germany), $\quad N^{2}, N^{2}, 7$-trimethylguanosine acetate $\left(\mathrm{m}^{2},{ }^{2}, \mathrm{G}\right)$ from Biolog (Bremen, Germany), pyridine from Gruessing (Filsum, Germany), and 1-methyl-L-histidine, purchased from Calbiochem/Merck (Nottingham, UK).

\section{Extraction of Nucleosides and Structurally Related Compounds from 24- $h$ Urine}

Previous to HPLC separation, the metabolites were isolated from urine by cis-diol specific affinity chromatography using affigel boronate (Biorad, Munich, Germany) by a slightly modified version of the method developed by Liebich et al. in 1997 [28]. A total of 300 $\mathrm{mL} 24-\mathrm{h}$ urine was processed in single steps of $20 \mathrm{~mL}$. The samples were alkalinized to $\mathrm{pH} 8.8$ with $2.5 \%$ ammonia solution and then put on the column (500 $\mathrm{mg}$ affigel boronate, column dimensions: $150 \times 15 \mathrm{~mm}$ ), preconditioned with $45 \mathrm{~mL}$ ammonium acetate solution, $\mathrm{pH} 8.8,0.25 \mathrm{M}$. Because of the high backpressure from the affigel boronate material, compressed air was applied throughout the extraction procedure to maintain a moderate flow rate. Nucleosides and other ribosylated compounds were bound reversibly and specifically at the $2^{\prime}, 3^{\prime}$-cis-diol group contained in the ribose structure. After washing with $20 \mathrm{~mL}$ ammonium acetate solution ( $\mathrm{pH} 8.8,0.25 \mathrm{M}$ ) and $6 \mathrm{~mL}$ methanol-water (2:8, vol/vol), elution was carried out with $50 \mathrm{~mL} 0.2 \mathrm{M}$ formic acid in methanol-water (1:1, vol/vol). The column was washed with $25 \mathrm{~mL}$ methanol-water (2:8, $\mathrm{vol} / \mathrm{vol}$ ) and reconditioned with $45 \mathrm{~mL}$ ammonium acetate solution ( $\mathrm{pH} 8.8,0.25 \mathrm{M}$ ). This was repeated 15 times to an extracted end volume of $300 \mathrm{~mL}$ urine. The collected elution solvent was removed using a rotary evaporator and the residue was dissolved again in $1 \mathrm{~mL}$ ammonium formate solution ( $\mathrm{pH}$ 5.0, $5 \mathrm{mM}$ ).

\section{Prepurification and Separation by Preparative TLC}

For further prepurification of the highly concentrated eluate, $300 \mu \mathrm{L}$ solution was put on a preparative TLC plate (SIL RP-18W/ $\mathrm{UV}_{254}, 1 \mathrm{~mm}$; Macherey-Nagel, Düren, Germany). Chromatographic separation was carried out over a total migration distance of $6 \mathrm{~cm}$ using a solvent composition of acetonitrile-water (1:6, vol/ $\mathrm{vol}$ ). The distance from starting line to solvent front was subdivided into twelve $0.5 \mathrm{~cm}$ fractions (fraction $1=$ $0-0.5 \mathrm{~cm}$, fraction $2=0.5-1.0 \mathrm{~cm}, \ldots)$. The plate material was separately scraped off and extracted twice with $20 \mathrm{~mL}$ portions of methanol-water (3:2, vol/vol + $1 \%$ formic acid) in an ultrasonic bath. Solid impurities were removed by centrifugation $\left(3000 \mathrm{~g}, 10 \mathrm{~min}, 20^{\circ} \mathrm{C}\right)$. The 12 extracts from the TLC plate fractions were concentrated by rotary evaporation and the residues were dissolved again in $1 \mathrm{~mL}$ ammonium formate solution ( $\mathrm{pH} 5,5 \mathrm{mM}$ ). Ten microliters of these samples were injected into the HPLC-MS system.

\section{Semipreparative HPLC for Isolation of} Selected Metabolites

Due to limitation of $\mathrm{MS}^{3}$ fragmentation in auto-LC MS runs, selected metabolites were isolated via semipreparative HPLC for IT $\mathrm{MS}^{n(n=4-6)}$ syringe pump infusion experiments. Therefore, a total of 250-300 $\mu \mathrm{L}$ of each TLC fraction was injected in portions of $50 \mu \mathrm{L}$ into the LC-IT MS system. Compounds chosen for additional mass spectrometric analysis were collected in $1.5 \mathrm{~mL}$ Eppendorf tubes at the corresponding retention times using the same gradient system as developed for the LC-auto $\mathrm{MS}^{3}$ runs (see text, LC-ESI-IT MS section). The obtained metabolite solutions were also used for high-resolution FT MS analysis.

\section{LC-ESI-IT MS}

The chromatographic separation of the urinary metabolites was performed on an Agilent 1100 Series HPLC system (Agilent, Waldbronn, Germany) consisting of a solvent degasser (G 1379 A), a binary capillary pump (G 1389), an autosampler ( $G 1313$ A), a column oven ( $G$ 1316 A), and a DAD (G 1315 B). The chromatographic system consisted of a Merck LiChroCART Superspher 100 RP-18 endcapped column $(125 \times 2.0$ mm i.d., $4 \mu \mathrm{m}$; Merck, Darmstadt, Germany) and a solvent system of 5 $\mathrm{mM}$ ammonium formate buffer, $\mathrm{pH}$ 5.0, and methanolwater (3:2, vol:vol $+0.1 \%$ formic acid). The column was operated at $25{ }^{\circ} \mathrm{C}$. The flow rate was set to $125 \mu \mathrm{L} / \mathrm{min}$ using a gradient as described by Kammerer et al. [19]. The LC system was coupled to a Bruker Esquire HCTion trap mass spectrometer (Bruker Daltonics, Bremen, Germany), equipped with an ESI source and operated in positive ion detection mode.

For LC-auto $\mathrm{MS}^{3}$ runs, the capillary voltage was set to $4 \mathrm{kV}$, the drying gas temperature in the electrospray source was set to $350{ }^{\circ} \mathrm{C}$, the nebulizer gas was set to 45 psi, and the drying gas to $9.0 \mathrm{~L} / \mathrm{min}$. The data were acquired in standard enhanced scan mode (8100 $m / z$ per s) over a mass range 200-600 Da. Previously identified major nucleoside compounds (e.g., 1-methyladenosine, 1-methylinosine, and $N^{2}, N^{2}$ dimethylguanosine) were excluded from $\mathrm{MS}^{n}$ selection for sensitive detection of minor compounds, coeluting in the HPLC separation.

Syringe pump (Cole Parmer, Vernon Hills, IL) infusion experiments for $\mathrm{MS}^{n}$ analysis were carried out at a flow rate of $300 \mu \mathrm{L} / \mathrm{h}$. The capillary voltage was set to $4 \mathrm{kV}$, the drying gas temperature in the electrospray source was set to $270{ }^{\circ} \mathrm{C}$, the nebulizer gas was set to 18 psi, and the drying gas to $6.0 \mathrm{~L} / \mathrm{min}$. The data were acquired in standard enhanced scan mode $(8100 \mathrm{~m} / \mathrm{z}$ per second) over a mass range 30-500 Da. All IT MS measurements were performed using the Bruker Esquire Control software, version 5.1. For postprocessing, Bruker Data Analysis version 3.1 was applied. 

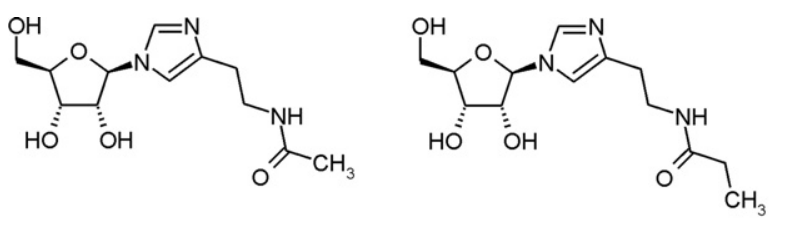

1-ribosyl-N-w-propionylhistamine

1-ribosyl-N-w-acetylhistamine

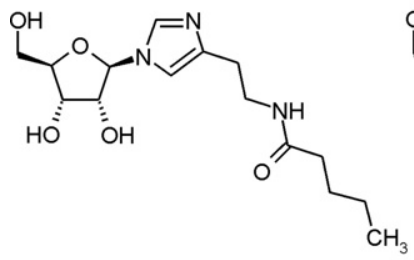

1-ribosyl-N-w-valerylhistamine

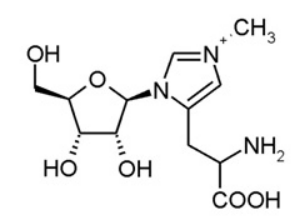

3-ribosyl-1-methyl-L-histidinium

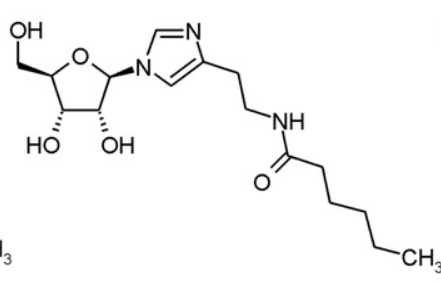

1-ribosyl-N-w-caproylhistamine

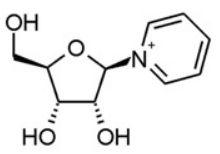

1-ribosyl-pyridinium

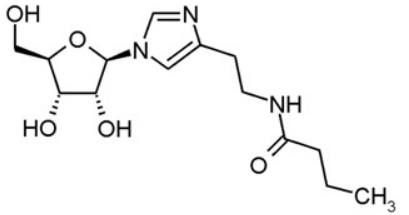

1-ribosyl-N-w-butyrylhistamine

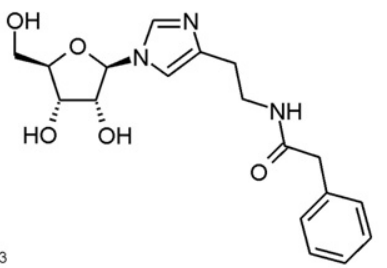

1-ribosyl-N-w-phenylacetylhistamine

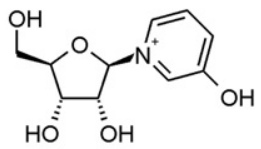

1-ribosyl-3-hydroxypyridinium

Figure 1. Identified structures of previously unknown urinary metabolites.

\section{ESI-FTICR MS}

ESI-FTICR MS measurements were carried out on a passively shielded 4.7 T APEX II ESI-FTICR mass spectrometer (Bruker Daltonics, Bremen, Germany). For data acquisition and postprocessing, the XMASS version 5.0.10 software (Bruker Daltonics) was used. Highresolution mass spectra were generated in the positive ionization mode with a $60^{\circ}$ off-axis grounded capillary sprayer needle (Analytica of Branford Inc., Branford, CT). The capillary exit voltage was adjusted to 15-25 V. For internal and external calibration, a homologous series of polyethylene glycols (PEG 400) was used. Samples were introduced via syringe pump (Cole Parmer, Vernon Hills, IL) infusion at a flow rate of 80 $\mu \mathrm{L} / \mathrm{h}$

\section{Results and Discussion}

In the present study, we demonstrate the potential of combined IT MS ${ }^{n}$ and FT MS analysis for the structural elucidation of ribosylated metabolites in the 24-h urine. Figure 1 shows the chemical structures of newly discovered metabolites in humans. To the authors' best knowledge, these derivatives have not been described previously in literature.

For preliminary metabolite screening, we applied auto-LC-IT $\mathrm{MS}^{3}$ runs [19] of the extracted urine fractions obtained by preparative TLC purification. Collision induced dissociation (CID) experiments enabled the generation of constant neutral loss (CNL) chromatograms, displaying only those compounds losing a defined functional group in the $\mathrm{MS}^{2}$ step (Figure 2).
In nucleosides and other ribosylated metabolites, this step is generally represented by the characteristic decay of the neutral sugar moiety at the fragile N-glycosidic bond. Loss of $132 \mathrm{Da}$ therefore is a strong indication for metabolites conjugated to an unaltered ribose. Modifications within the ribose moiety show a corresponding mass shift, e.g., neutral loss of methylthioribose (162 Da) in 5'-deoxy-5'methylthioadenosine (MTA) [19, 27]. The generally

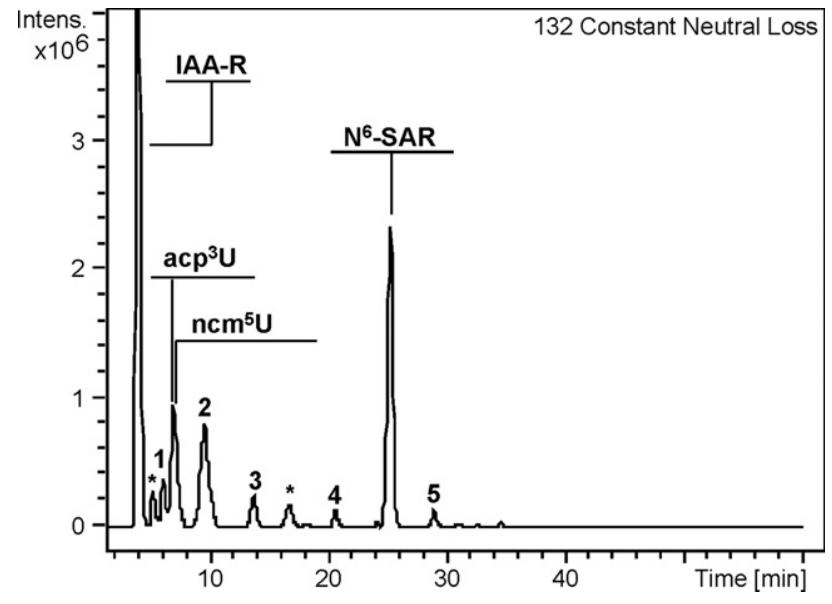

Figure 2. Processed 132 constant neutral loss trace (loss of ribose) of TLC plate fraction 11 from a head and neck cancer patient. Abbreviations for analyzed metabolites: IAA-R: 1-ribosyl-imidazole4-acetic acid, acp ${ }^{3} \mathrm{U}$ : 3-(3-aminocarboxypropyl)-uridine, $\mathrm{ncm}^{5} \mathrm{U}$ : 5-carbamoylmethyluridine $\mathrm{N}^{6}$-SAR: $N^{6}$-succinyloadenosine. Numbered compounds already identified in previous studies [19, 25] ( 1 = cytidine, $2=3$-methylcytidine, $3=3,4-\mathrm{PCNR}, 4=$ 2,5-PCNR, $5=1$-methylinosine). Asterisks: currently under investigation. 
observed dissociation of known sugar moieties in $\mathrm{MS}^{2}$ enables the metabolite identification via the remaining heterocycles, which are commercially available more often than their ribosylated analogs.

Fragmentation patterns generated by auto LC-MS ${ }^{3}$ measurements are limited, especially when hypermodified structures are analyzed. Thus, we isolated selected metabolites via semipreparative HPLC for syringe pump infusion experiments, enabling $\mathrm{MS}^{n(n=4-6)}$ analysis (Table 1). Beside the common neutral losses in CID fragmentation processes, $\mathrm{H}_{2} \mathrm{O}$ and $\mathrm{MeOH}$ addition was observed (Table 1, italic fragments). These neutral gains have already been described in several mass spectrometric studies [29-31]. Impurities in the applied collision gas $\left(\mathrm{H}_{2} \mathrm{O}\right)$ as well as solvent molecules $(\mathrm{MeOH}$, $\mathrm{H}_{2} \mathrm{O}$ ) passing from the ion source into the MS have been discussed as possible sources for this phenomenon. We were able to confirm the process of possible neutral gain reactions in our ion trap mass spectrometer by analyzing the $N^{2}, N^{2}, 7$-trimethylguanosine standard in different solvents via syringe pump infusion. The proposed addition of residual methanol solvent molecules in the $\mathrm{MS}^{4}$ fragmentation step of the semipreparatively isolated $N^{2}, N^{2}, 7$-trimethylguanosine (Table 1 , no. 4 , sample solved in methanol/ammonium formate buffer) was no longer observable when the compound was analyzed in pure acetonitrile.

The accurate masses determined by FTICR MS experiments enabled the generation of molecular formulae for the unknown ribosylated metabolites (Table 2). We could narrow down the list of possible molecular compositions by considering known properties of the analyzed compound class. A minimum of five carbon atoms, four oxygens, and one nitrogen for the labile $\mathrm{C}-\mathrm{N}$ glycosidic bond as required for the conjugated ribose moiety along with $\mathrm{H}$ and $\mathrm{S}$ were chosen as constraints for mass analysis. As all compounds show regular MS $^{3}$ fragmentation behavior in the IT MS measurements, we could exclude sodium and potassium adducts, which usually do not show $\mathrm{MS}^{3}$ fragmentation of the remaining heterocycle. The generated molecular formulae were also used for calculating the corresponding double-bond equivalents (DBE) via formula (1), yielding additional hints on the structural identity (double bonds, ring closures) of unknown metabolites.

$$
D B E=\frac{(2 n+2)-(m-k)}{2} \quad \text { for } \mathrm{C}_{n} \mathrm{H}_{m} \mathrm{O}_{l} \mathrm{~N}_{k}
$$

Sulfur-oxygen double bonds (e.g., in sulfoxides) are not considered in the resulting DBE value as the basic elements generally contribute only in their lowest state of valence. In some cases, the extremely low concentration and ion suppression effects by the PEG calibrant precluded internal calibration, resulting in somewhat poorer mass accuracy.

\section{Modified Nucleosides}

With the presented analytical approach, we were able to identify seven compounds, which turned out to be modified nucleosides. In detail, these were the metabolites with $\mathrm{m} / \mathrm{z} 302,346,398,326,333,427$, and 459 (Tables, no. 1-7). All mentioned compounds show a CNL of $132 \mathrm{Da}$ in the auto-LC IT MS ${ }^{3}$ screening runs, indicating a nonmodified ribose moiety attached to the corresponding heterocycle.

Compound $m / z$ 302, occurring in TLC fraction 11, showed consecutive expulsion of $\mathrm{NH}_{3}$ and $\mathrm{CO}$, presumably originating from a terminal carbamoyl-moiety and $\mathrm{HNCO}$ pointing at a uridine-based structure. Considering the molecular formula $\left[\mathrm{C}_{11} \mathrm{H}_{16} \mathrm{~N}_{3} \mathrm{O}_{7}\right]^{+}$obtained by FT MS analysis, the metabolite could be identified as 5-carbamoylmethyluridine. Metabolite $\mathrm{m} / \mathrm{z} 346$ from TLC fraction 11 showed characteristic fragmentation behavior in IT MS ${ }^{n}$ analysis. The MS ${ }^{4}$ step led to the loss of a formic acid moiety (46 Da) and corresponding carbon chain extended acids. In $\mathrm{MS}^{5}$, a loss of 43 (HNCO) was observed, pointing at uridine as basic element. FT MS analysis revealed a molecular composition of $\left[\mathrm{C}_{13} \mathrm{H}_{20} \mathrm{~N}_{3} \mathrm{O}_{8}\right]^{+}$, verifying the proposed ribonucleoside structure as 3-(3-aminocarboxypropyl)uridine. Both mentioned ribonucleosides have previously been reported by Chheda et al. as urinary constituents [32, 33].

A metabolite with $\mathrm{m} / \mathrm{z} 398$ occurred primarily in TLC fraction 2. The RNA database [26] lists two possible structures, namely 2-methylthio- $N^{6}$-(cis-hydroxyiso-pentenyl)adenosine and 5-taurinomethyl-2-thiouridine. With the obtained molecular formula suggestion $\left[\mathrm{C}_{16} \mathrm{H}_{24} \mathrm{~N}_{5} \mathrm{O}_{5} \mathrm{~S}\right]^{+}$we were able to exclude the latter. The molecular formula fit the adenosine derivative. Additional hints were obtained in the performed $\mathrm{MS}^{n}$ analysis, showing characteristic decays of $\mathrm{C}_{4} \mathrm{H}_{8} \mathrm{O}$ and $\mathrm{C}_{5} \mathrm{H}_{8} \mathrm{O}$ from the $\mathrm{N}^{6}$ substituted, hydroxylated carbon side chain in $\mathrm{MS}^{3}$ and $\mathrm{CH}_{3} \mathrm{SH}$ from the methylthioadenosine scaffold in MS ${ }^{4}$. Combining this information, the metabolite could be identified as 2-methylthio- $\mathrm{N}^{6}$-(cis-hydroxyiso-pentenyl)adenosine. The occurrence of this modified nucleoside in human urine has not been verified previously.

A main component of the analyzed cis-diol metabolite pattern with $\mathrm{m} / \mathrm{z} 326$ was detected with peak retention in TLC fraction 2. The measured mass/ charge ratio of 326.146067 could be attributed to a molecular composition of $\left[\mathrm{C}_{13} \mathrm{H}_{20} \mathrm{~N}_{5} \mathrm{O}_{5}\right]^{+}$, exactly matching that of the well-known urinary nucleoside $N^{2}, N^{2}, 7$-trimethylguanosine. Characteristic neutral losses of $\left(\mathrm{CH}_{3}\right)_{2} \mathrm{NH}$ and $\left(\mathrm{CH}_{3}\right)_{2} \mathrm{NCN}$ in $\mathrm{MS}^{3}$ support the presumption of a hypermethylated guanosine scaffold. As this modified nucleoside is commercially available, we were able to verify the assigned structure via similar fragmentation patterns and retention time.

Another metabolite with $\mathrm{m} / \mathrm{z} 333$ was detected in TLC fraction 7 . Three feasible nucleoside structures are listed in the RNA database (5-oxyacetic acid methyl ester-2-uridine, 5-carboxy-hydroxymethyl methyl ester- 


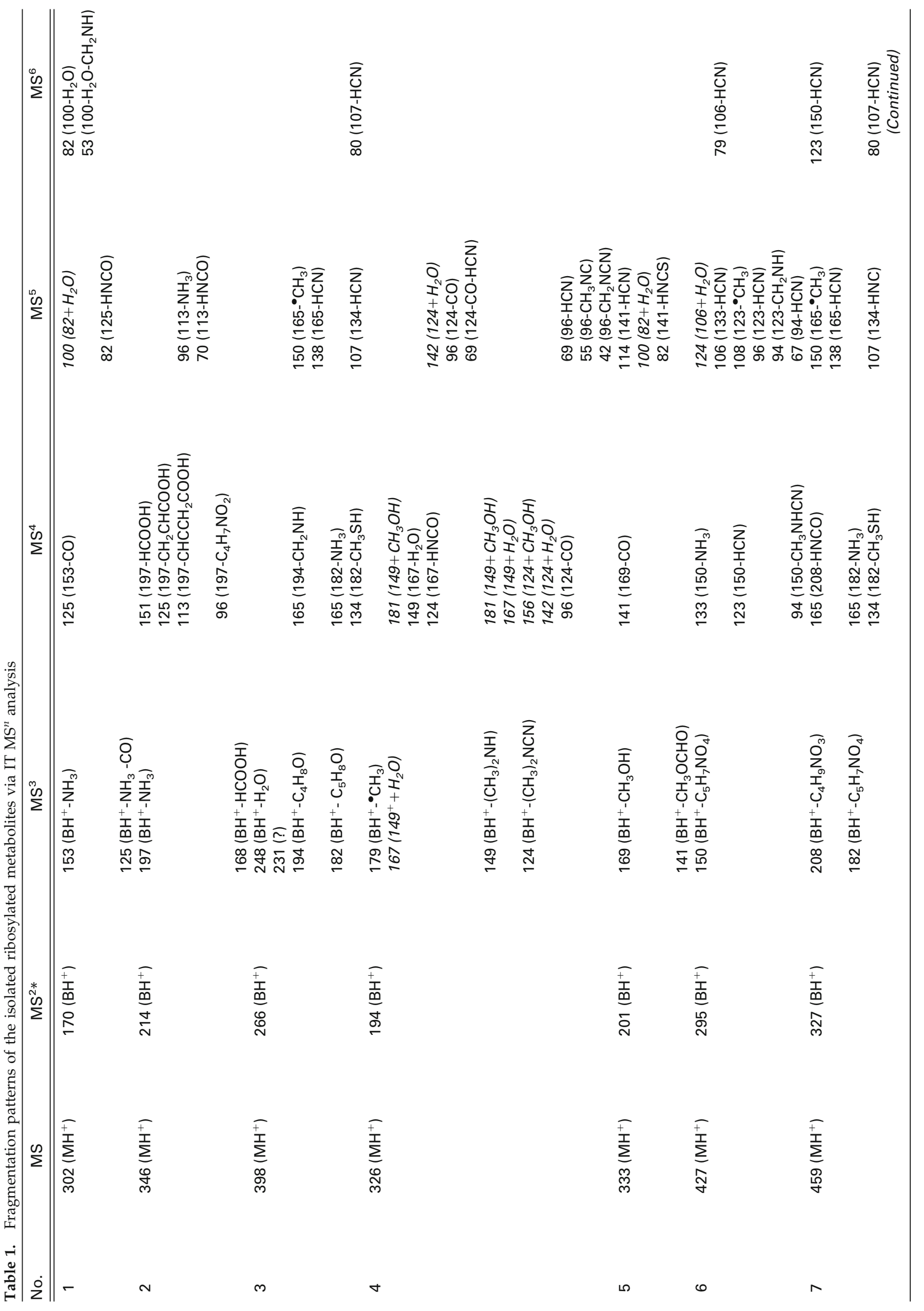




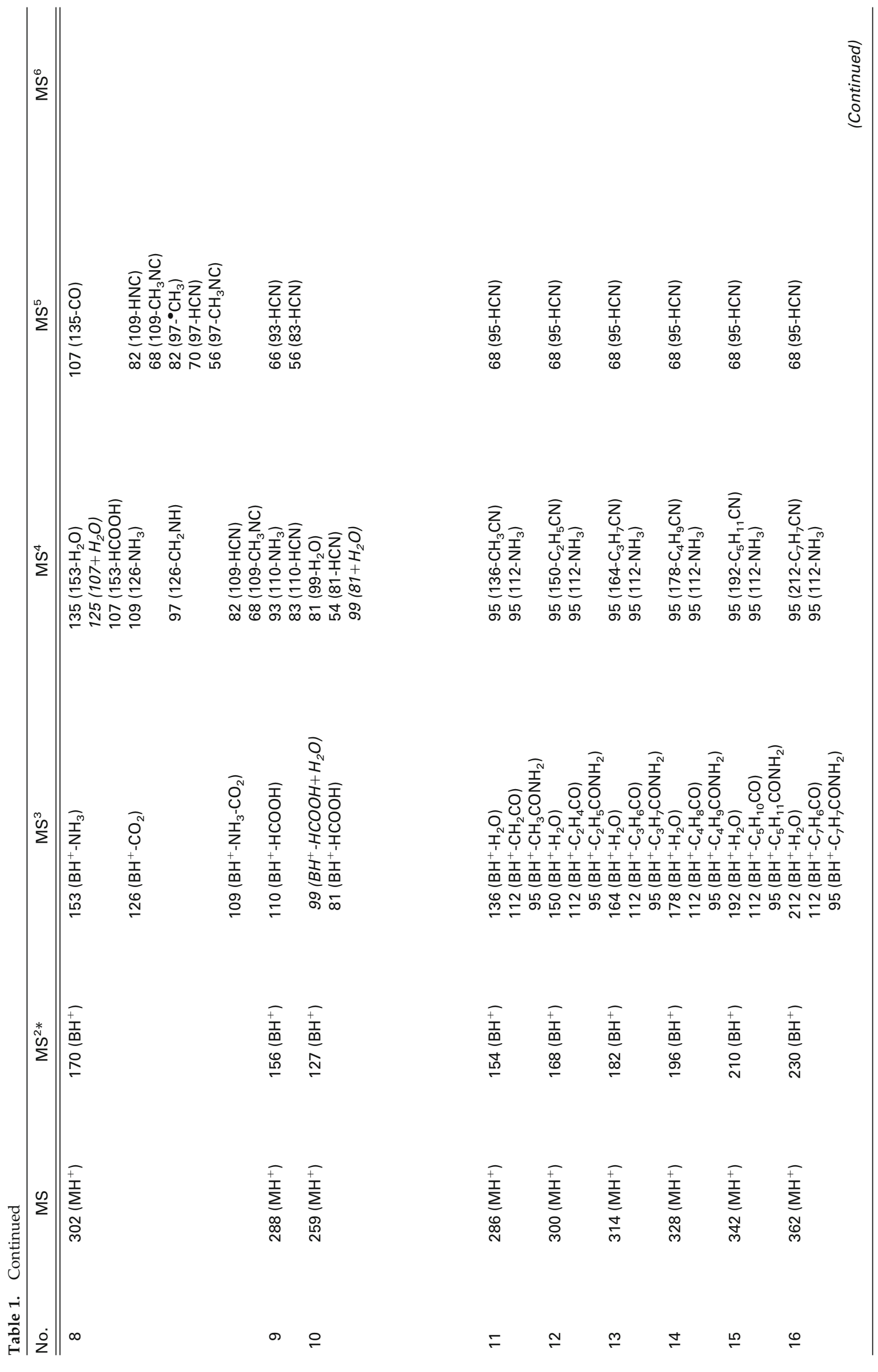




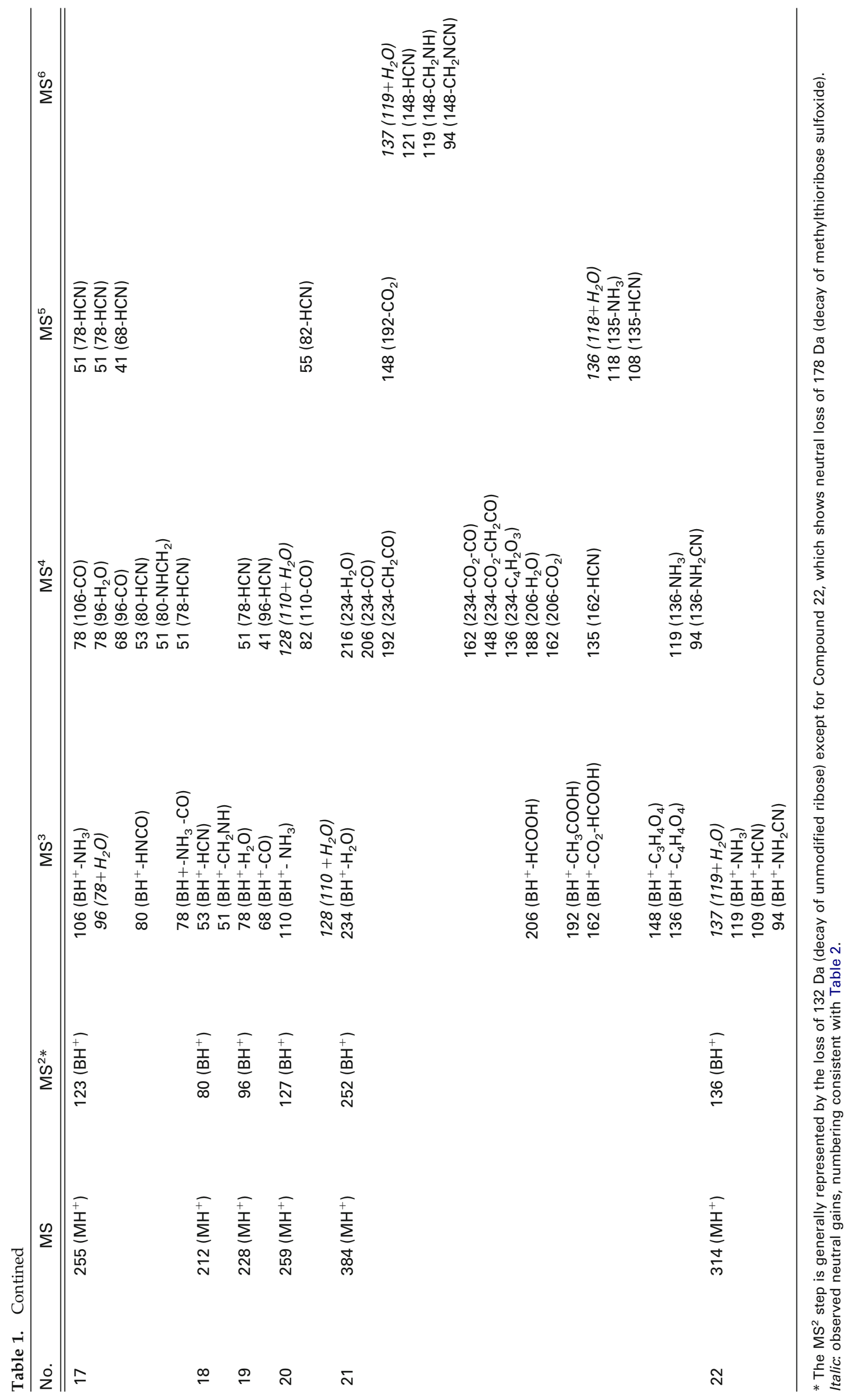


Table 2. Accurate@nass@neasurements@nd@nolecular@ormulae@eneration@f@he@solated@ibosylated@netabolites@ia FTICRQMS@nalysis

\begin{tabular}{|c|c|c|c|c|c|c|}
\hline No. & $\mathrm{RT}$ & $\begin{array}{l}\text { Mass meas. } \\
{\left[\mathrm{MH}^{+}\right]^{*}}\end{array}$ & $\begin{array}{c}\text { Molecular } \\
\text { formula }\left[\mathrm{MH}^{+}\right]\end{array}$ & $\begin{array}{l}\text { ppm } \\
\text { error** }\end{array}$ & DBE & Compound identified as \\
\hline \multicolumn{7}{|c|}{ Modified nucleosides } \\
\hline 1 & 7.0 & 302.09821 & $\mathrm{C}_{11} \mathrm{H}_{16} \mathrm{~N}_{3} \mathrm{O}_{7}$ & $-0.22(\mathrm{IC})$ & 6 & 5-carbamoylmethyluridine \\
\hline 2 & 7.0 & 346.12442 & $\mathrm{C}_{13} \mathrm{H}_{20} \mathrm{~N}_{3} \mathrm{O}_{8}$ & $-0.22(\mathrm{IC})$ & 6 & 3-(3-aminocarboxypropyl)-uridine \\
\hline 3 & 40.0 & 398.148 & $\mathrm{C}_{16} \mathrm{H}_{24} \mathrm{~N}_{5} \mathrm{O}_{5} \mathrm{~S}$ & $-3.9(\mathrm{EC})$ & 8 & 2-methylthio- $N^{6}$-(cis-hydroxyisopentenyl)-adenosine \\
\hline 4 & 41.5 & 326.1461 & $\mathrm{C}_{13} \mathrm{H}_{20} \mathrm{~N}_{5} \mathrm{O}_{5}$ & $0.53(\mathrm{IC})$ & 7 & $N^{2}, N^{2}, 7$-trimethylguanosine \\
\hline 5 & 43.0 & 333.07506 & $\mathrm{C}_{12} \mathrm{H}_{17} \mathrm{~N}_{2} \mathrm{O}_{7} \mathrm{~S}$ & $-0.13(\mathrm{IC})$ & 6 & 5-methoxycarbonylmethyl-2-thiouridine \\
\hline 6 & 49.5 & 427.1574 & $\mathrm{C}_{16} \mathrm{H}_{23} \mathrm{~N}_{6} \mathrm{O}_{8}$ & $0.56(\mathrm{IC})$ & 9 & $N^{6}$-methyl-N $N^{6}$-threonylcarbamoyladenosine \\
\hline 7 & 50.0 & 459.1291 & $\mathrm{C}_{16} \mathrm{H}_{23} \mathrm{~N}_{6} \mathrm{O}_{8} \mathrm{~S}$ & $-0.40(\mathrm{IC})$ & 9 & 2-methylthio- $N^{6}$-threonylcarbamoyladenosine \\
\hline \multicolumn{7}{|c|}{ Histidine metabolites } \\
\hline 8 & 3.0 & 302.133 & $\mathrm{C}_{12} \mathrm{H}_{20} \mathrm{~N}_{3} \mathrm{O}_{6}$ & $-5.2(\mathrm{EC})$ & 5 & 3-ribosyl-1-methyl-L-histidinium \\
\hline 9 & 3.5 & 288.117 & $\mathrm{C}_{11} \mathrm{H}_{18} \mathrm{~N}_{3} \mathrm{O}_{6}$ & $-5.4(E C)$ & 5 & 1-ribosyl-L-histidine \\
\hline 10 & 4.0 & 259.09249 & $\mathrm{C}_{10} \mathrm{H}_{15} \mathrm{~N}_{2} \mathrm{O}_{6}$ & $0.12(\mathrm{IC})$ & 5 & 1-ribosyl-imidazole-4-acetic acid \\
\hline 11 & 10.0 & 286.13980 & $\mathrm{C}_{12} \mathrm{H}_{20} \mathrm{~N}_{3} \mathrm{O}_{5}$ & 0.17 (IC) & 5 & 1-ribosyl- $N$ - $\omega$-acetylhistamine \\
\hline 12 & 19.5 & 300.15545 & $\mathrm{C}_{13} \mathrm{H}_{22} \mathrm{~N}_{3} \mathrm{O}_{5}$ & $0.17(\mathrm{IC})$ & 5 & 1-ribosyl- $\mathrm{N}$ - $\omega$-propionylhistamine \\
\hline 13 & 30.0 & 314.1712 & $\mathrm{C}_{14} \mathrm{H}_{24} \mathrm{~N}_{3} \mathrm{O}_{5}$ & 0.46 (IC) & 5 & 1-ribosyl- $N$ - $\omega$-butyrylhistamine \\
\hline 14 & 44.0 & 328.18659 & $\mathrm{C}_{15} \mathrm{H}_{26} \mathrm{~N}_{3} \mathrm{O}_{5}$ & $-0.33(\mathrm{IC})$ & 5 & 1-ribosyl- $N$ - $\omega$-valerylhistamine \\
\hline 15 & 51.5 & 342.2026 & $\mathrm{C}_{16} \mathrm{H}_{28} \mathrm{~N}_{3} \mathrm{O}_{5}$ & $0.80(\mathrm{IC})$ & 5 & 1-ribosyl- $N$ - $\omega$-caproyllhistamine \\
\hline 16 & 46.5 & 362.170 & $\mathrm{C}_{18} \mathrm{H}_{24} \mathrm{~N}_{3} \mathrm{O}_{5}$ & $-1.7(\mathrm{EC})$ & 9 & 1-ribosyl- $N$ - $\omega$-phenylacetylhistamine \\
\hline \multicolumn{7}{|c|}{ Nicotinate/nicotinamide metabolites } \\
\hline 17 & 4.0 & 255.0970 & $\mathrm{C}_{11} \mathrm{H}_{15} \mathrm{~N}_{2} \mathrm{O}_{5}$ & $-2.1(\mathrm{EC})$ & 6 & 1-ribosyl-3-carbamoylpyridinium \\
\hline 18 & 5.0 & 212.0919 & $\mathrm{C}_{10} \mathrm{H}_{14} \mathrm{NO}_{4}$ & $0.67(\mathrm{IC})$ & 5 & 1-ribosyl-pyridinium \\
\hline 19 & 7.0 & 228.08656 & $\mathrm{C}_{10} \mathrm{H}_{14} \mathrm{NO}_{5}$ & -0.37 (IC) & 5 & 1-ribosyl-3-hydroxypyridinium \\
\hline \multicolumn{7}{|c|}{ Metabolites from the purine biosynthesis } \\
\hline 20 & 10.0 & 259.10371 & $\mathrm{C}_{9} \mathrm{H}_{15} \mathrm{~N}_{4} \mathrm{O}_{5}$ & $0.066(\mathrm{IC})$ & 5 & $\begin{array}{l}\text { 1-ribosyl-4-carboxamido-5-aminoimidazole (AICA } \\
\text { riboside) }\end{array}$ \\
\hline 21 & 25.0 & 384.1153 & $\mathrm{C}_{14} \mathrm{H}_{18} \mathrm{~N}_{5} \mathrm{O}_{8}$ & $0.78(\mathrm{IC})$ & 9 & $N^{6}$-succinyloadenosine \\
\hline \multicolumn{7}{|c|}{ Metabolite from the polyamine/methionine cycle } \\
\hline 22 & 32.0 & 314.091755 & $\mathrm{C}_{11} \mathrm{H}_{16} \mathrm{~N}_{5} \mathrm{O}_{4} \mathrm{~S}$ & $0.013(\mathrm{IC})$ & 7 & $5^{\prime}$-deoxy-5'-methyl-thioadenosine sulfoxide \\
\hline
\end{tabular}

* Rounded values, reported up to the most significant decimal.

** IC: internal calibration, EC: external calibration, rounded values.

Italic: occurrence in human urine reported for the first time, bold: previously unknown metabolites.

Numbering consistent with Table 1. RT: retention time, DBE: double bond equivalents.

2-uridine,@and@5-methoxycarbonylmethyl-2-thiouridine) [26].CTheđirstC2@ompounds@have@identical@molecular formulae@hereas@hat@f(Compound@@iffers.๑rom@he FT@S@nalysis@hich@indicated@@nolecular@ormula@f $\left[\mathrm{C}_{12} \mathrm{H}_{17} \mathrm{~N}_{2} \mathrm{O}_{7} \mathrm{~S}\right]^{+}$, $₫$ he@ulfur@lacking@ridine@erivatives could@e@xcluded.(Due@o@he@xactly@natching@nolecular@ormula@s@ell@s@@itting@and@haracteristic@MS ${ }^{n}$ fragmentation@pattern@e.g., @lecay@ofmethanol@n@MS ${ }^{3}$,

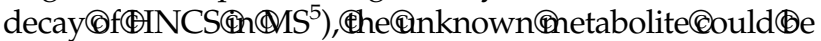
identified@s(5-methoxycarbonylmethyl-2-thiouridine. (The occurrence@his@nodified@ucleoside@n@human@urine has@lso@ot@een@erified@reviously.

InबLC@raction@, $($ wo $@$ netabolites@ith@n/z 427@nd $\mathrm{m} / \mathrm{z}$ 459@were@detected@and@analyzed.@For@the@first compound@n@ccurate@nass/charge@atio@f@27.157426 was@etermined@ia@T@MS@ith@@orresponding@molecular@ormula@f $\left.₫ \mathrm{C}_{16} \mathrm{H}_{23} \mathrm{~N}_{6} \mathrm{O}_{8}\right]^{+}$. CAn@RNA@database search@ffered@wo@ossible@hypermodified@ucleoside structures@with@identical@elemental@composition: $\mathbb{C N}^{6}$ hydroxynorvalylcarbamoyladenosine@and $\odot N^{6}$-methyl$N^{6}$-threonylcarbamoyladenosine.CFigureÇ@exemplarily shows@the@analytical@benefit@ofChigher@ragmentation steps@n@he@nalysis@f@omplex@ibonucleosides.CThe unknown@metabolite@howed@n@lmost@unspecific@rag-

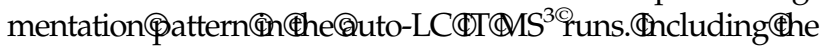

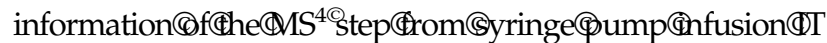
MS $^{n}$ experiments, $(4)$ as as

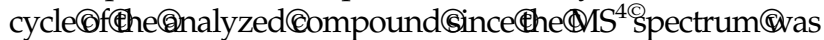
identical@o@he@MS ${ }^{3}$ spectrum@f 9 he@ommercially@vailable modified@ucleoside $\mathbb{V}^{6}$-methyladenosine. Accordingly, (4he unknown@ompound@ould@e@dentified@s@ $@ V^{6}$-methyl- $N^{6}$ threonylcarbamoyladenosine $\left(\mathrm{m}^{6} \mathrm{t}^{6} \mathrm{~A}\right)$. CTo@he@uthors' (best

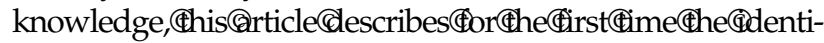
fication@f@his@ypermodified@ucleoside@n@human@urine.

Another@nodified@ucleoside@ith@n/z 459, (previously unknown@s@onstituent@f@uman@rine,@ould@e@dentified@n@his@tudy.Similar@o@he@atter@ompound, (@nore

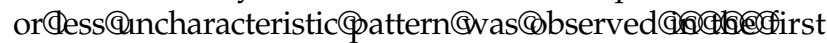
three $₫$ ragmentation@teps.@n@lemental@omposition@f $\left[\mathrm{C}_{16} \mathrm{~N}_{23} \mathrm{~N}_{6} \mathrm{O}_{8} \mathrm{~S}\right]^{+\bigodot^{+}}$was@obtained@via@FT@MS@analysis,

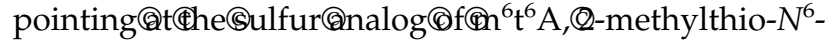
threonylcarbamoyladenosine. $\Phi$ his@as @erified $\oplus y @ M S(-)$ analysis@with@the@distinctive@neutral@osses@of@43@Da

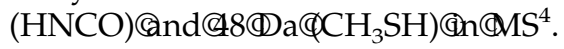

\section{Histidine Metabolites}

Many@f@he@unknown@ompounds@in@the@et@of isolated@urinary@is-diols@urned@ut@o@be@ibosylated histidine@netabolites. 


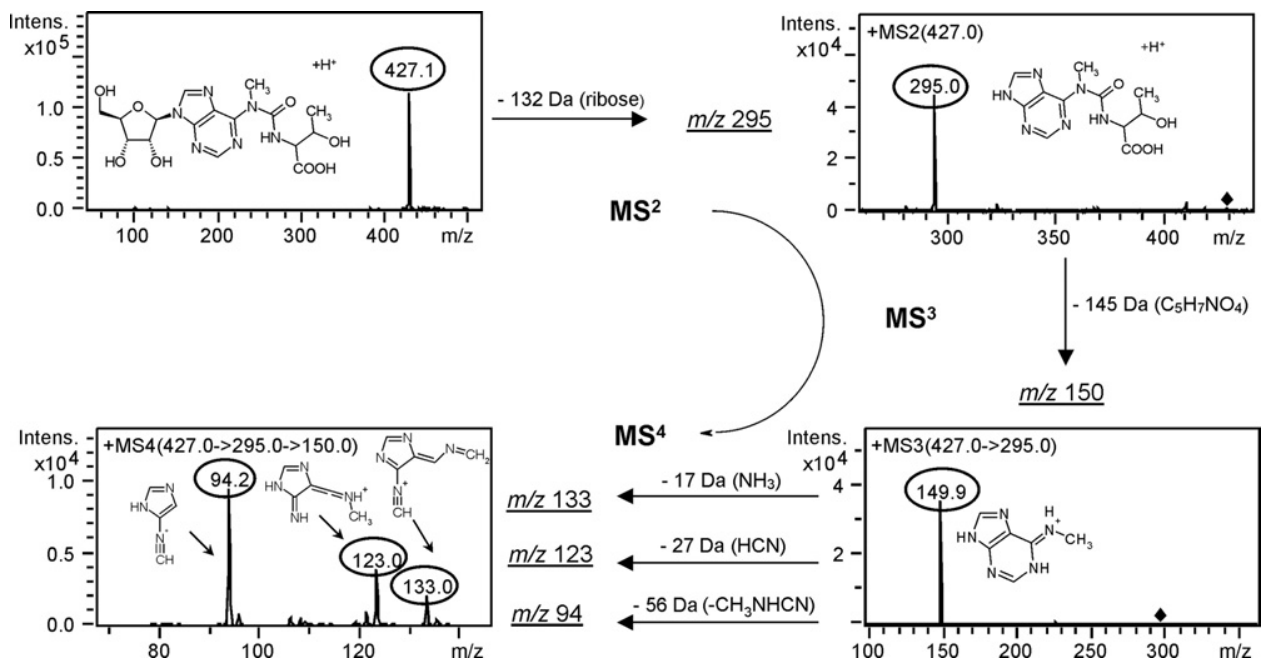

Figure 3. IT MS $\mathrm{M}^{4}$ fragmentation pathway for the identified compound $N^{6}$-methyl- $N^{6}$-threonylcarbamoyladenosine. MS ${ }^{4}$ spectrum is identical with $\mathrm{MS}^{3}$ spectrum of $N^{6}$-methyladenosine.

Two@ompounds@ith@n/z 288@nd@02@Tables,@o.@,(8)

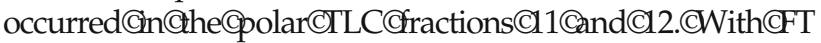
MSCanalysis, Che Cmolecular@formulae $₫\left[\mathrm{C}_{12} \mathrm{H}_{20} \mathrm{~N}_{3} \mathrm{O}_{6}\right]^{+}$and $\left[\mathrm{C}_{11} \mathrm{H}_{18} \mathrm{~N}_{3} \mathrm{O}_{6}\right]^{+} \mathrm{C}_{\text {were }}$ determined, Cindicating@compound m/z 302థo@e@@nethylated@nalog@f@ompound@n/z 288. The@atter@ould@e@dentified@s@-ribosyl-L-histidine@ia the@xactly@itting@nolecular@omposition@nd@omparison@f $₫ \mathrm{MS}^{n}$ fragmentation $@$ with@he@-histidine@standard.@haracteristic@ragmentation@moieties@f(he@histidine@tructure@ere $₫$ he $₫ o s s @ f \mathbb{H} H_{3}$ and $₫ H C O O H \oplus r o m$ the@terminal@side@chain, Cand@subsequent@onsecutive HCN@xpulsion $\oplus$ rom $\oplus$ hemaining@midazole@caffold. The@dentified@ompound@-ribosyl-L-histidine@has@l-

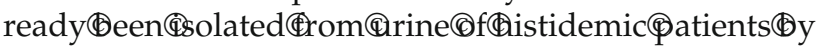
Imamura@t@1.థ34].

Methylated@histidines@(1-@and@3-methylhistidine) have@been@inalyzed@y@Piraud@t@1.@ia@ESI-MS/MS using@@riple@uadrupole@nass@pectrometerథ35].Фis-

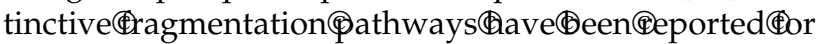
the@wo@osition@somers, @ith@hat@f@-methylhistidine

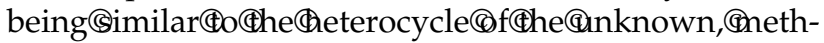
ylated@histidine@iboside@n@his@tudy.đdentical@ragmentation@ehavior@ould@e@onfirmed $\oplus y \mathbb{M S}^{n}$ analysis of@the@1-methylhistidine@standard@with@our@ion@trap system. $₫ o @$ ohe@uthors' $($ est $₫$ nowledge, $₫$ he@netabolite 3-ribosyl-1-methyl-L-histidinium $\odot$ identified $\odot$ has $\odot$ not been@escribed@reviously@n@iterature.

A@ompound@ith@n/z 259థTables, (10.@0), @ccurring(ฺn TLC $₫$ ractions@1@nd@2థlas@lready@een@nalyzed@n@ur research@roup@y@neans@f@ombined $\Phi T \pitchfork S @$ and $\oplus$ C-TOF

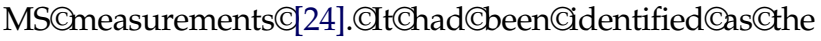
histamine@netabolite@-ribosyl-imidazole-4-acetic@cid@nd was@onfirmed@n@he@resent@tudy@with@@ower@pm error@nd@MS ${ }^{n}$ fragmentation@omparison@with@he@ommercially@vailable@tandard@midazole-4-acetic@cid.

A@eries@f@etabolites@ith@@onsecutive@nass@hift of@4Фa @m/z 286,@00,@314,(328,@342;(Gables,@o.@1-15) and@similar@fragmentation@behavior@was@detected@in

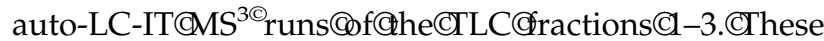
compounds@ll@howed@ibose@ecay@ne $₫ \mathrm{MS}^{2}$ step@s well@s@vater@limination@nd@wo@haracteristic,@basic fragments@/z 112@nd@5@n@he@MS ${ }^{3 @}$ step.

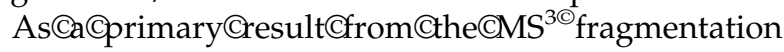
pathways,@he@nalyzed@ompounds@resumably@hare a@basic@tructural@lement $(m / z$ 112@nd@5)@nd@@ide chain@longated@y@nethylene@nsertion.@his@vas@onsistent@with@he@hromatographic@properties,@howing an@increasing@etardation@vith@ncreasing@arbon@hain length@and@thus@decreasing@polarity@on@the@applied RP-18@olumn@Figure@4).@FT@MS@measurements@onfirmed@he@hypothesis@f@@ethylene@nass@hift@f@4 Da via molecular formula suggestion based on accurate mass determination (Table 2).

The most obvious endogenous compounds showing a linear carbon chain extension are the fatty acids. In literature, no cross-linked reactions between RNA metabolites and fatty acids are described. Screening the human histidine metabolism@n@theđKEGG@PATHWAY@Database@http:/ / www.genome.jp/kegg/pathway.html), @weđfound@a@compound with fitting properties, concerning the possible heterocycle of the ribosylated compound $\mathrm{m} / \mathrm{z} 286$. The metabolite 4- $\beta$-acetylaminoethyl-imidazole (trivial name: $\mathrm{N}$ - $\omega$-acetylhistamine) is formed via addition of acetic acid to the histamine scaffold. The corresponding elemental composition $\left[\mathrm{C}_{7} \mathrm{H}_{12} \mathrm{~N}_{3} \mathrm{O}\right]^{+}$was identical with that of the unknown compound $\mathrm{m} / \mathrm{z} 286\left[\mathrm{C}_{12} \mathrm{H}_{20} \mathrm{~N}_{3} \mathrm{O}_{5}\right]^{+}$minus the ribose moiety $\left[-\mathrm{C}_{5} \mathrm{H}_{8} \mathrm{O}_{4}\right]$. Final confirmation of the proposed structure was achieved via comparative $\mathrm{MS}^{n}$ fragmentation with the commercially available heterocycle standard $N$ - $\omega$-acetylhistamine. Combining the observed mass shift of 14 Da proved in FT MS measurements of $\mathrm{m} / \mathrm{z} 286,300,314,328$, and 342 with the expulsion of an increasing side-chain moiety (286 acetonitrile, 300 - propiononitrile, 314 - butyronitrile, 328 - pentanonitrile, 342 - hexanonitrile) in the $\mathrm{MS}^{4}$ step (see Table 1), the metabolite series was structurally 


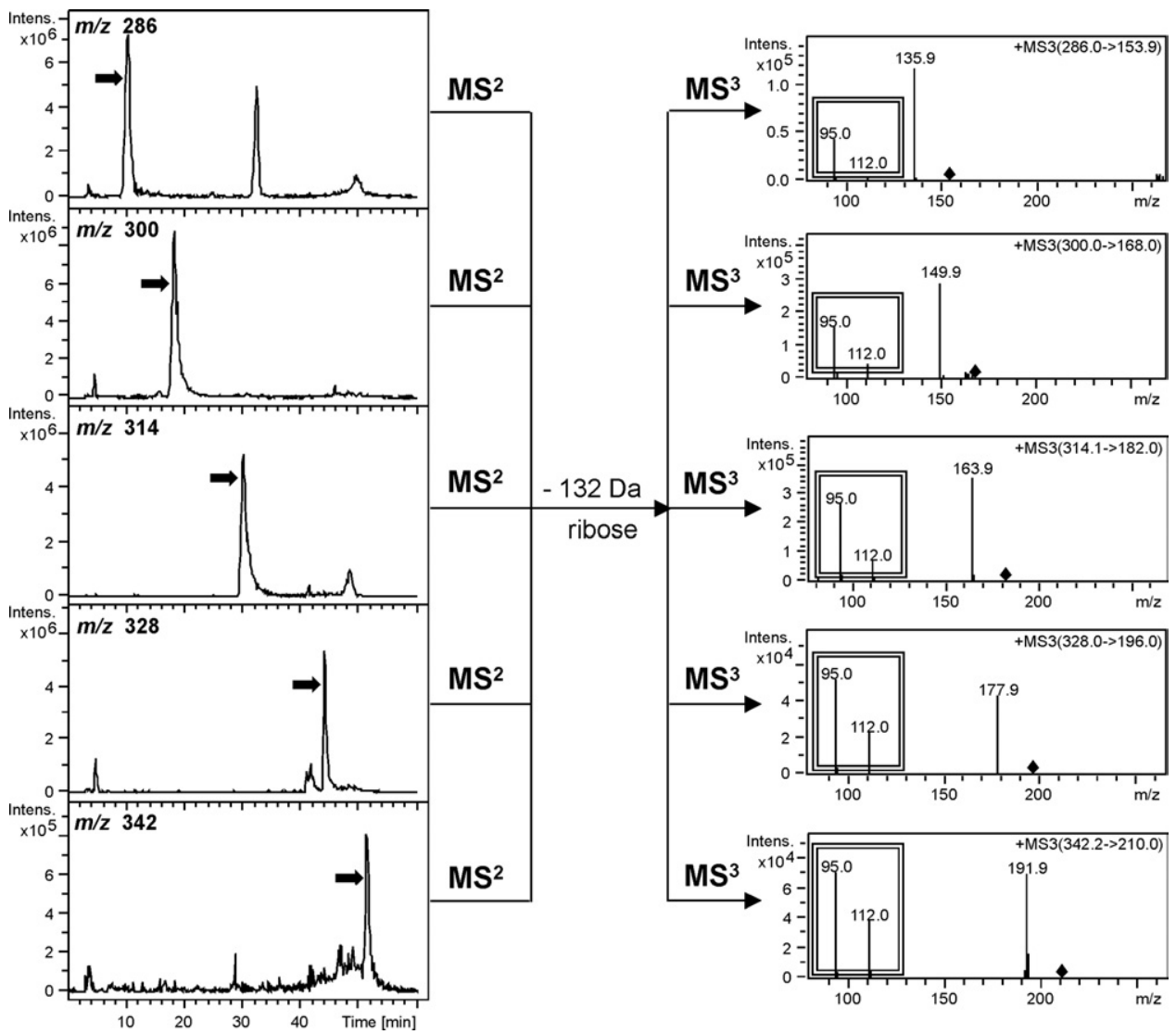

Figure 4. Metabolite series of ribosylated histamine-fatty acid conjugates (Tables, no. 11-15), showing increasing retardation on RP-18 column and similar properties in the corresponding fragmentation patterns.

elucidated as ribosylated histamines, conjugated to linear short-chain fatty acids at the $\mathrm{N}^{\omega}$-position (see Figure 1). A proposal for the proceeding fragmentation mechanisms is shown in Scheme 1. With the basic structure identified, the biochemical origin was unknown since no chain elongation of acetylhistamine is known in human metabolism. However, a formation of homologous short-chain fatty acid (C2-C4)-histamine conjugates $(N-\omega$-acetylhistamine, $N$ - $\omega$-propionylhistamine, $\mathrm{N}$ - $\omega$-butyrylhistamine) has been reported in context with the activity of intestinal bacteria [36]. These metabolites have been detected in human urine with a suggested qualitative and quantitative dependency of the measured excretory pattern upon intestinal amino acid transport, composition of the bacterial flora, and dietary aspects (e.g., fermentation of dietary fiber).

The corresponding ribosylated conjugates have not been described previously in literature. There is no additional information about possible processes of resorption and ribosylation. This should be the subject of further investigations. The probable bacterial origin of these metabolites led to their exclusion from our ongoing cancer biomarker studies.

Related to but not exactly consistent with the methylene shift properties of the last-mentioned histamine metabolites was a compound with $m / z 362$ (Tables, no.
16), found in TLC fraction 4 . The fragmentation pathway of this metabolite also showed water elimination and the two basic fragments $\mathrm{m} / \mathrm{z} 112$ and 95, suggesting the similar basic structure of a histamine riboside conjugated to a carbon side chain. An elemental composition of $\left[\mathrm{C}_{18} \mathrm{H}_{24} \mathrm{~N}_{3} \mathrm{O}_{5}\right]^{+}$was obtained possessing nine double-bond equivalents (compounds 286-342 all have 5 DBE). Considering the molecular formula and the DBE value, the only possible structure could be a benzene ring system (four DBE) in the conjugated carbon side chain. A structure matching the required properties is phenylacetic acid, also known as a bacterial degradation product of nonabsorbed phenylalanine in the human intestinal lumen [37]. The combined mass spectrometric data confirmed the conjugation of this presumably bacterial metabolite to a histamine scaffold to give rise to the previously unknown urinary compound 1-ribosyl- $N$ - $\omega$-phenylacetylhistamine.

\section{Nicotinate/Nicotinamide Metabolites}

A main component of the urinary cis-diol metabolite pattern with $\mathrm{m} / \mathrm{z} 255$ (Tables, no. 17) could be detected in nearly all fractions of the TLC separation. FT MS measurements revealed a molecular composition of $\left[\mathrm{C}_{11} \mathrm{H}_{15} \mathrm{~N}_{2} \mathrm{O}_{5}\right]^{+}$. Consecutive neutral loss of $\mathrm{NH}_{3}$ and 


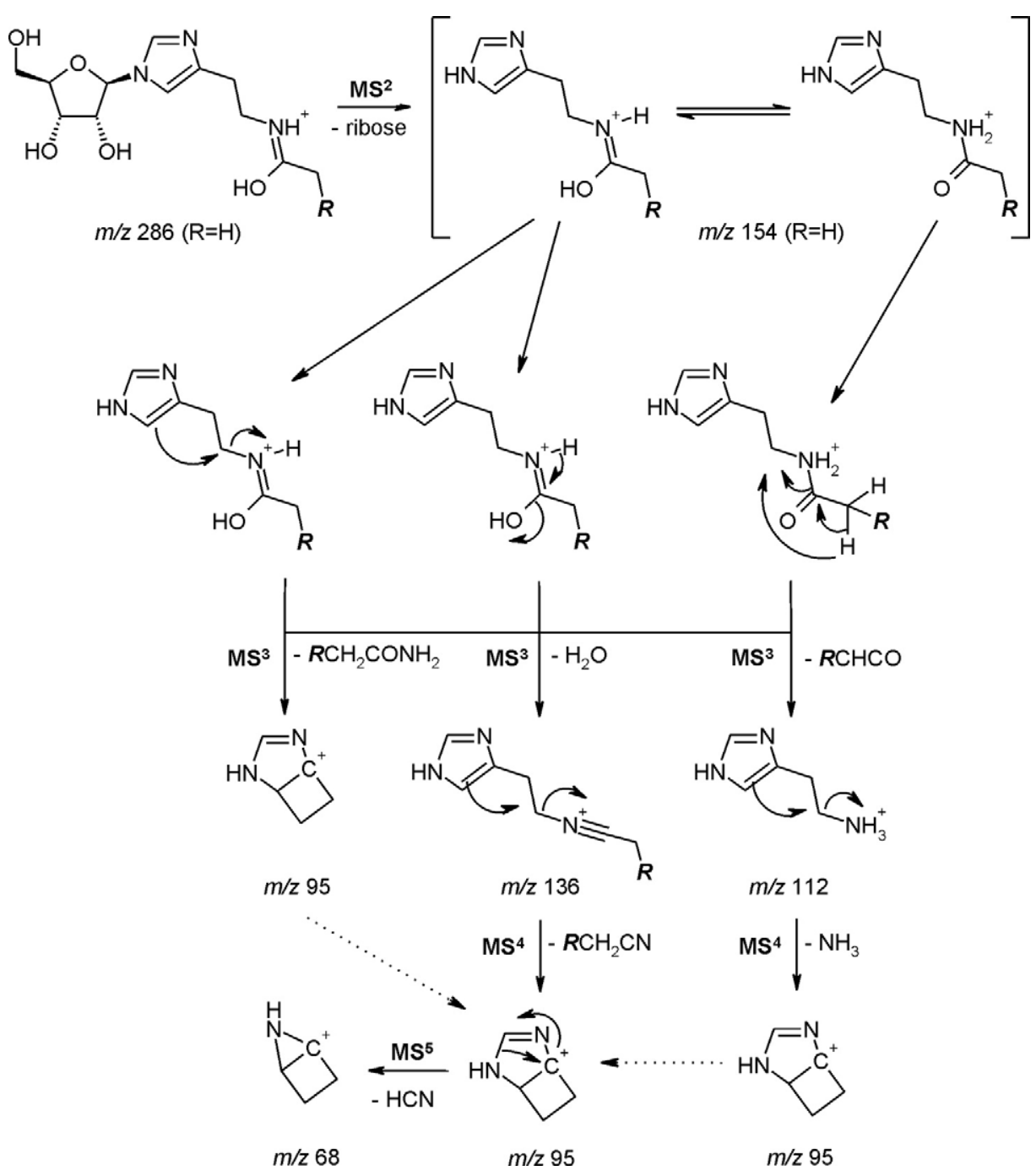

Scheme 1. Fragmentation mechanism proposal for the metabolite series of ribosylated histaminefatty acid conjugates (Tables, no. 11-16); $\mathrm{R}=-\mathrm{H}(\mathrm{m} / \mathrm{z} 286),-\mathrm{CH}_{3}(\mathrm{~m} / \mathrm{z} 300),-\mathrm{CH}_{2} \mathrm{CH}_{3}(\mathrm{~m} / \mathrm{z} 314)$, $-\left(\mathrm{CH}_{2}\right)_{2} \mathrm{CH}_{3}(\mathrm{~m} / \mathrm{z} 328),-\left(\mathrm{CH}_{2}\right)_{3} \mathrm{CH}_{3}(\mathrm{~m} / \mathrm{z} 342),-\mathrm{C}_{6} \mathrm{H}_{5}(\mathrm{~m} / \mathrm{z} 362)$.

$\mathrm{CO}$ in IT MS ${ }^{3}$ could be attributed to the cleavage of a terminal carbamoyl moiety. The second analyzed fragmentation pathway via expulsion of $\mathrm{HNCO}$ in $\mathrm{MS}^{3}$ subsequently showed distinctive double elimination of the pyridine nitrogen as $\mathrm{HCN}$ and $\mathrm{NHCH}_{2}$, respectively. A compound matching the obtained MS data is 1-ribosyl-3carbamoylpyridinium, also known as ribosylated nicotinamide. IT MS analysis of the nicotinamide base standard verified this presumption. Morris et al. first reported the isolation of this metabolite from human urine [38].

In the TLC fractions 3 and 4, two metabolites with $\mathrm{m} / \mathrm{z} 212$ and 228 (Tables, no. 18, 19) were detected. Both compounds show the common neutral loss of 132 in the $\mathrm{MS}^{2}$ step and were semipreparatively isolated for further mass spectrometric analysis. The corresponding elemental compositions were $\left[\mathrm{C}_{10} \mathrm{H}_{14} \mathrm{NO}_{4}\right]^{+}$and $\left[\mathrm{C}_{10} \mathrm{H}_{14} \mathrm{NO}_{5}\right]^{+}$, respectively, and argue for $\mathrm{m} / \mathrm{z} 228$ to be the oxidized counterpart of $\mathrm{m} / \mathrm{z} 212$. The latter could be identified as the previously unknown 1-ribosylpyridinium via the generated molecular formula with a resulting DBE value of 5 as well as comparative $\mathrm{MS}^{n}$ analysis with the pyridine standard. $\mathrm{MS}^{n}$ analysis of compound $\mathrm{m} / \mathrm{z} 228$ showed elimination of carbon monoxide in $\mathrm{MS}^{3}$ and loss of $\mathrm{HCN}$ in the $\mathrm{MS}^{4}$ step, pointing to a ribosylated hydroxypyridine structure with unknown position (ortho, meta or para) of the hydroxy function. Comparative $\mathrm{MS}^{n}$ studies of the hydroxypyridine standards available with the heterocycle of $\mathrm{m} / \mathrm{z} 228$ led to a characteristic distinction between the three possible position isomers via differences in the relative intensities of the two fragments $\mathrm{m} / \mathrm{z} 78$ and 68 . As the $\mathrm{MS}^{2}$ spectrum of 3-hydroxypyridine exactly fit the $\mathrm{MS}^{3}$ spectrum of the ribosylated hydroxypyridine (Figure 5), compound $\mathrm{m} / \mathrm{z} 228$ could be identified as the previously unknown, urinary metabolite 1-ribosyl-3-hydroxypyridinium.

\section{Purine Biosynthesis}

Two compounds deriving from the purine biosynthesis could be identified in this study. The metabolite 1-ribosyl- 


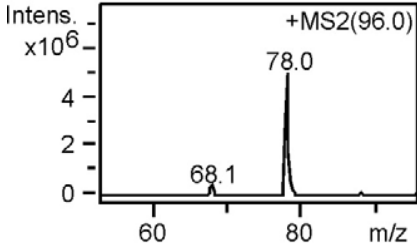

2-hydroxypyridine

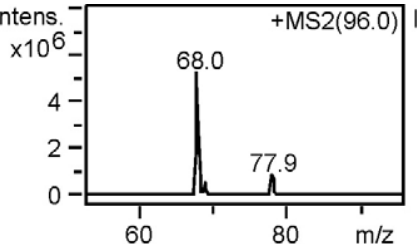

3-hydroxypyridine

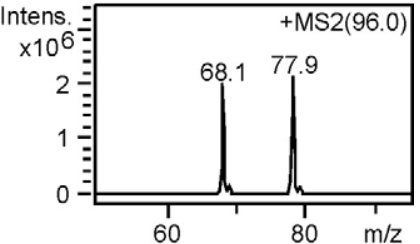

4-hydroxypyridine

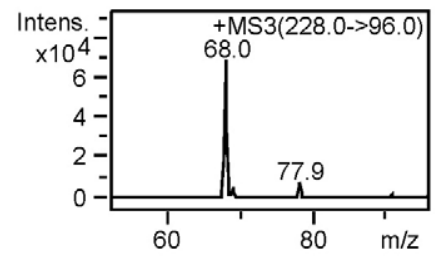

1-ribosyl-3-hydroxypyridinium $(\mathrm{m} / \mathrm{z} 228)$

Figure 5. Identification of position isomer 3-hydroxypyridine as heterocycle compound of the previously unknown, urinary metabolite 1-ribosyl-3-hydroxypyridinium $(\mathrm{m} / \mathrm{z} 228)$ via comparison of relative intensities of fragments 78 (loss of water), and 68 (loss of CO) in IT MS ${ }^{n}$ analysis.

4-carboxamido-5-aminoimidazole $(\mathrm{m} / \mathrm{z}$ 259; Tables, no. 20), a well-known urinary constituent [39], occurred in TLC fraction 9. With FT MS analysis, the fitting molecular formula suggestion of $\left[\mathrm{C}_{9} \mathrm{H}_{15} \mathrm{~N}_{4} \mathrm{O}_{5}\right]^{+}$was obtained. $\mathrm{MS}^{n}$ studies showed consecutive elimination of $\mathrm{NH}_{3}$, $\mathrm{CO}$, and $\mathrm{HCN}$ moieties after the common cleavage of the $\mathrm{C}-\mathrm{N}$ glycosidic bond. Fragmentation behavior and retention time were identical with the commercially available standard compound and led to the unambiguous structural elucidation of the commonly named AICA riboside.

A metabolite with $\mathrm{m} / \mathrm{z} 384$ (tables, no. 21) was primarily detected in the TLC fractions 10 and $11 . \mathrm{MS}^{n}$ studies of this compound resulted in extensive fragmentation patterns, marked by complex expulsion of carbon oxides and carboxylic acid residues. The cleavage of a $\mathrm{C}_{4} \mathrm{H}_{4} \mathrm{O}_{4}$-moiety in $\mathrm{MS}^{3}$ resulted in a fragment with $\mathrm{m} / \mathrm{z} 136$, which subsequently fragmented under elimination of $\mathrm{NH}_{3}$ and $\mathrm{NH}_{2} \mathrm{CN}$. As the latter fragmentation pathway is characteristic for the adenine base $(\mathrm{m} / \mathrm{z}$ 136), we suggested the unknown compound to be the hypermodified adenosine structure, $N^{6}$-succinyloadenosine. This was confirmed by the obtained molecular composition of $\left[\mathrm{C}_{14} \mathrm{H}_{18} \mathrm{~N}_{5} \mathrm{O}_{8}\right]^{+}$and comparative $\mathrm{MS}^{n}$ analysis with the commercially available, monophosphosphorylated analog adenylosuccinic acid. Chheda already isolated and characterized $N^{6}$-succinyloadenosine from urine of colon cancer patients and healthy volunteers [40].

\section{Methionine/Polyamine Cycle}

An unusual neutral loss (178 Da) was observed in $\mathrm{MS}^{2}$ of a metabolite with $\mathrm{m} / \mathrm{z} 314$ (tables, no. 22) in TLC fraction 3, pointing to a modified ribose structure attached to the heterocycle. The latter could be identified as adenine via the characteristic fragmentation pattern, including the loss of $\mathrm{NH}_{3}, \mathrm{HCN}$, and $\mathrm{NH}_{2} \mathrm{CN}$.
The metabolite MTA, a byproduct of the polyamine biosynthesis [27], shows similar properties. This compound loses the methylthioribose moiety in $\mathrm{MS}^{2}$ (162 $\mathrm{Da})$, resulting in the protonated adenine nucleobase. Combining the oxygen shift in the neutral loss values $(162>178)$ with the obtained molecular formula $\left[\mathrm{C}_{11} \mathrm{H}_{16} \mathrm{~N}_{5} \mathrm{O}_{4} \mathrm{~S}\right]^{+}$, we were able to identify the metabolite as the already known sulfoxide analog of MTA, $5^{\prime}$-deoxy5'-methyl-thioadenosine sulfoxide (MTA-SO) [41].

\section{Conclusions}

This work demonstrates the potential of combined IT $\mathrm{MS}^{n}$ and FT MS analysis as a powerful tool for structural elucidation of urinary metabolites. In this basic, first-step approach of our ongoing metabolic profiling project, we were able to identify 22 compounds deriving from different metabolic pathways such as RNA metabolism, histidine metabolism, nicotinate/nicotinamide metabolism, purine biosynthesis, and methionine/polyamine cycle. The occurrence of four modified nucleosides is described for the first time in human urine. Also, a previously unknown series of ribosylated histamines conjugated to homologues short-chain fatty acids and phenylacetic acid, respectively, were revealed in this study. The compounds 1-ribosyl-3-hydroxypyridinium, 1-ribosylpyridinium, and 3-ribosyl-1-methyl--L-histidinium were found as novel urinary constituents. The identification of these unknown compounds may lead to a reinvestigation of the corresponding metabolic pathways. It has to be pointed out that none of the identified metabolites from this study showed a specific, tumor-related occurrence as they were present in all screened urine samples and even in previously analyzed urines from healthy volunteers. However, structural elucidation enables the constitution of a more reliable urinary metabolic profile due to the assignment and subsequent exclusion of 
metabolites with presumably nonhuman origin. Due to the interconnectivity of the considered pathways, tumor-related perturbations in the RNA subset potentially provoke implications on the others and vice versa. Consequently, the second step of our continuing metabolic profiling project will be the utilization of bioinformatic classification algorithms for quantitative pattern recognition of urinary ribosylated metabolites.

\section{Acknowledgments}

The authors thank the hospital staff of the Department of Radiation Oncology and the Department of Otorhinolaryngology, Head and Neck Surgery, University Hospital Tübingen, for the support in the recruitment process.

\section{References}

1. Paik, S. Incorporating Genomics into the Cancer Clinical Trial Process. Semin. Oncol. 2001, 28, 305-309.

2. Kim, S. Y.; Hahn, W. C. Cancer Genomics: Integrating Form and Function. Carcinogenesis 2007, 28, 1387-1392.

3. Rajapakse, J. C.; Duan, K.; Yeo, W. K. Proteomic Cancer Classification with Mass Spectrometry Data. Am. J. Pharmacogenomics 2005, 5, 281-292.

4. Maurya, P.; Meleady, P.; Dowling, P.; Clynes, M. Proteomic Approaches for Serum Biomarker Discovery in Cancer. Anticancer Res. 2007, 27, 1247-1255.

5. Griffin, J. L.; Shockcor, J. P. Metabolic Profiles of Cancer Cells. Nat. Rev. Cancer 2004, 4, 551-561.

6. Kind, T.; Tolstikov, V.; Fiehn, O.; Weiss, R. H. A Comprehensive Urinary Metabolomic Approach for Identifying Kidney Cancer. Anal. Biochem. 2007, 363, 185-195.

7. Gamache, P. H.; Meyer, D. F.; Granger, M. C.; Acworth, I. N. Metabolomic Applications of Electrochemistry/Mass Spectrometry. J. Am. Soc. Mass Spectrom. 2004, 15, 1717-1726.

8. Ryan, D.; Robards, K. Metabolomics: The greatest Omics of Them All? Anal. Chem. 2006, 78, 7954-7958.

9. Tormey, D. C.; Waalkes, T. P.; Gehrke, C. W. Biological Markers in Breast Carcinoma-Clinical Correlations with Pseudouridine, N2,N2Dimethylguanosine, and 1-Methylinosine. J. Surg. Oncol. 1980, 14, 267-273

10. Itoh, K.; Konno, T.; Sasaki, T.; Ishiwata, S.; Ishida, N.; Misugaki, M. Relationship of Urinary Pseudouridine and 1-Methyladenosine to Activity of Leukemia and Lymphoma. Clin. Chim. Acta 1992, 206, 181-189.

11. Nakano, K.; Shindo, K.; Yasaka, T.; Yamamoto, H. Reversed-Phase High-Performance Liquid Cchromatographic Investigation of Mucosal Nucleosides and Bases and Urinary Modified Nucleosides of Gastrointestinal Cancer Patients. J. Chromatogr. 1985, 343, 21-33.

12. Waalkes, T. P.; Abeloff, M. D.; Ettinger, D. S.; Woo, K. B.; Gehrke, C. W.; Kuo, K. C.; Borek, E. Modified Ribonucleosides as Biological Markers for Patients with Small Cell Carcinoma of the Lung. Eur. J. Cancer Clin. Oncol. 1982, 18, 1267-1274.

13. Borek, E.; Baliga, B. S.; Gehrke, C. W.; Kuo, C. W.; Belman, S.; Troll, W.; Waalkes, T. P. High Turnover Rate of Transfer RNA in Tumor Tissue. Cancer Res. 1977, 37, 3362-3366.

14. Tsutsui, E.; Srinivasan, P. R.; Borek, E. TRNA Methylases in Tumors of Animal and Human Origin. Proc. Natl. Acad. Sci. U.S.A. 1966, 56, 1003-1009.

15. Dudley, E.; Lemiere, F.; Van Dongen, W.; Langridge, J. I; El-Sharkawi, S.; Games, D. E.; Esmans, E. L.; Newton, R. P. Analysis of Urinary Nucleosides. III. Identification. of $5^{\prime}$-Deoxycytidine in Urine of a patient with head and neck cancer. Rapid Commun. Mass Spectrom. 2003, 17, 1132-1136.

16. Gehrke, C. W.; Kuo, K. C. Ribonucleoside Analysis by Reversed-Phase High-Performance Liquid Chromatography. J. Chromatogr. 1989, 471, 3-36.

17. Xu, G.; Schmid, H. R.; Lu, X.; Liebich, H. M.; Lu, P. Excretion Pattern Investigation of Urinary Normal and Modified Nucleosides of Breast Cancer Patients by RP-HPLC and Factor Analysis Method. Biomed. Chromatogr. 2000, 14, 459-463.

18. Xu, G.; Lu, X.; Zhang, Y.; Lu, P.; Di, S. C.; Lehmann, R.; Liebich, H. Two Approaches for Determining the Urinary Excretion Patterns of Nucleosides-HPLC and CE. Sepu 1999, 17, 97-101.
19. Kammerer, B.; Frickenschmidt, A.; Muller, C. E.; Laufer, S.; Gleiter, C. H.; Liebich, H. Mass Spectrometric Identification of Modified Urinary Nucleosides Used as Potential Biomedical Markers by LC-ITMS Coupling. Anal. Bioanal. Chem. 2005, 382, 1017-1026.

20. Qian, M.; Yang, S.; Wu, H.; Majumdar, P.; Leigh, N.; Glaser, R. Ammonia Elimination from Protonated Nucleobases and Related Synthetic Substrates. J. Am. Soc. Mass. Spectrom. 2007, 18, 2040-2057.

21. Zhang, Q.; Wang, Y. Differentiation of 2'-O- and 3'-O-Methylated Ribonucleosides by Tandem Mass Spectrometry. J. Am. Soc. Mass Spectrom. 2006, 17, 1096-1099.

22. Takeda, N.; Nakamura, M.; Yoshizumi, H.; Tatematsu, A. Structura Characterization of Modified Nucleosides in tRNA Hydrolysates by Frit-Fast Atom Bombardment Liquid Chromatography/Mass Spectrometry. Biol. Mass Spectrom. 1994, 23, 465-474.

23. Crow, F. W.; Tomer, K. B.; Gross, M. L.; McCloskey, J. A.; Bergstrom, D. E. Fast Atom Bombardment Combined with Tandem Mass Spectrometry for the Determination of Nucleosides. Anal. Biochem. 1984, 139, 243-262.

24. Bullinger, D.; Frickenschmidt, A.; Pelzing, M.; Zey, T.; Zurek, G.; Laufer, S.; Kammerer, B. Identification of Urinary Nucleosides by ESI-TOF-MS. LC-GC Eur. 2005, 16-17.

25. Kammerer, B.; Frickenschmidt, A.; Gleiter, C. H.; Laufer, S.; Liebich, H. MALDI-TOF MS Analysis of Urinary Nucleosides. J. Am. Soc. Mass Spectrom. 2005, 16, 940-947.

26. McCloskey, J. A.; Crain, P. F. The RNA Modification Database-1998 Nucleic Acids Res. 1998, 26, 196-197.

27. Bullinger, D.; Neubauer, H.; Fehm, T.; Laufer, S; Gleiter, C. H. Kammerer, B. Metabolic Signature of Breast Cancer Cell Line MCF-7: Profiling of Modified Nucleosides via LC-IT MS Coupling. BMC Biochem. 2007, 8, 25

28. Liebich, H. M.; Di, S. C.; Wixforth, A.; Schmid, H. R. Quantitation of Urinary Nucleosides by High-Performance Liquid Chromatography. J. Chromatogr. A 1997, 763, 193-197.

29. Barcelo-Barrachina, E.; Moyano, E.; Galceran, M. T. Determination of Heterocyclic Amines by Liquid Chromatography-Quadrupole Time-ofFlight Mass Spectrometry. J. Chromatogr. A 2004, 1054, 409-418.

30. Tuytten, R.; Lemiere, F.; Van Dongen, W.; Esmans, E. L.; Witters, E. Herrebout, W.; Van der Veken, B.; Dudley, E.; Newton, R. P. Intriguing Mass Spectrometric Behavior of Guanosine Under Low Energy Collision-Induced Dissociation: $\mathrm{H}_{2} \mathrm{O}$ Adduct Formation and Gas-Phase Reactions in the Collision Cell. J. Am. Soc. Mass Spectrom. 2005, 16, 1291-1304.

31. Frycak, P.; Huskova, R.; Adam, T.; Lemr, K. Atmospheric Pressure Ionization Mass Spectrometry of Purine and Pyrimidine Markers of Inherited Metabolic Disorders. J. Mass Spectrom. 2002, 37, 1242-1248.

32. Chheda, G. B.; Patrzyc, H. B.; Tworek, H. A.; Dutta, S. P. Isolation and Characterization of 5-Carbamoylmethyluridine and 5-Carbamoylmethyl2-Thiouridine from Human Urine. Nucleosides Nucleotides 1999, 18, 21552173 .

33. Chheda, G. B.; Tworek, H. A.; Bhargava, A. K.; Rachlin, E.; Dutta S. P.; Patrzyc, H. B. Isolation and Characterization of 3-(3-Amino-3 Carboxypropyl)Uridine from Human Urine. Nucleosides Nucleotides $1988,7,417-429$.

34. Imamura, I.; Watanabe, T.; Sakamoto, Y.; Wakamiya, T.; Shiba, T.; Hase, Y.; Tsuruhara, T.; Wada, H. N. $\tau$-Ribosylhistidine, a Novel Histidine Derivative in Urine of Histidinemic Patients. Isolation, Structure, and Tissue Level. J. Biol. Chem. 1985, 260, 10528-10530.

35. Piraud, M.; Vianey-Saban, C.; Petritis, K.; Elfakir, C.; Steghens, J.; Morla A.; Bouchu, D. ESI-MS/MS Analysis of Underivatized Amino Acids: A New Tool for the Diagnosis of Inherited Disorders of Amino Acid Metabolism. Fragmentation Study of 79 Molecules of Biological Interest in Positive and Negative Ionization mode. Rapid Commun. Mass Spectrom. 2003, 17, 1297-1311.

36. van der Heiden, C.; Wadman, S. K.; de Bree, P. K.; Wauters, E. A Increased Urinary Imidazolepropionic acid, N-Acetylhistamine, and Other Imidazole Compounds in Patients with Intestinal Disorders. Clin. Chim. Acta 1972, 39, 201-214.

37. van der Heiden, C.; Wauters, E. A.; Duran, M.; Wadman, S. K.; Ketting, D. Gas Chromatographic Analysis of Urinary Tyrosine and Phenylalanine Metabolites in Patients with Gastrointestinal Disorders. Clin. Chim. Acta 1971, 34, 289-296.

38. Morris, G. S.; Simmonds, H. A.; Davies, P. M. Use of Biological Fluids for the Rapid Diagnosis of Potentially Lethal Inherited Disorders of Human Purine and Pyrimidine Metabolism. Biomed. Chromatogr. 1986, 1, 109-118.

39. Schram, K. H. Urinary Nucleosides. Mass Spectrom. Rev. 1998, 17, 131-251.

40. Chheda, G. B. Isolation and Characterization of N6-Succinyladenosine from Human Urine. Nucleic Acids Res. 1977, 4, 739-746.

41. Mills, J. S.; Mills, G. C.; McAdoo, D. J. Isolation and Identification of 5'-Methylthioadenosine Sulfoxide from Human Urine. Nucleosides $\mathrm{Nu}$ cleotides 1983, 2, 465-478. 